\title{
Effect of enveloping and disinfection methods on artefact formation on enveloped PSP plate images
}

\author{
Umut Pamukcu ${ }^{1} \cdot$ Hatice Tetik ${ }^{1} \cdot$ Ilkay Peker $^{1} \cdot$ Ozge Karadag Atas ${ }^{2} \cdot$ Zuhre Zafersoy Akarslan $^{1}$
}

Received: 1 August 2021 / Accepted: 9 January 2022 / Published online: 22 January 2022

(c) The Author(s) under exclusive licence to Japanese Society for Oral and Maxillofacial Radiology 2022

\begin{abstract}
Objectives To investigate the artefacts caused by different disinfection and protection methods that can be used for infection control of photostimulable phosphor (PSP) plates.

Methods The plates that were enveloped with single or double envelopes were sprayed with an alcohol-containing solution or wiped with an alcohol-containing tissue. Four PSP groups with two plates in each group were formed $(A=$ wiping single envelope, $B=$ wiping double envelopes, $C=$ spraying onto single envelope, and $D=$ spraying onto double envelopes). Any artefacts $(1=$ no artefact, $2=$ presence of artefact less than $0.5 \mathrm{~cm}$ wide, and $3=$ presence of artefact larger than $0.5 \mathrm{~cm}$ wide $)$ on the 12 acquired images were evaluated.

Results Artefacts (score-3) occurred on the images of Group C-2 PSP plate after the 3rd exposure. According to the KruskalWallis test the difference between the artefact score of the four methods was found significant. Post-hoc comparisons showed the Group $C$ artefact scores were higher than the others and the difference was significant. The total time of enveloping and disinfection processes for groups was; $A=6.30 \mathrm{~min}, B=7.58 \mathrm{~min}, C=5.48 \mathrm{~min}$, and $D=7.14 \mathrm{~min}$.

Conclusions Regardless of the number of envelopes, wiping with a tissue was less likely to cause artefacts, while spraying was reliable only when double envelopes were used. However, using a tissue and double envelopes, which are less risky in terms of artefact, causes time loss, difficulty in manipulation, environmental pollution and high cost.
\end{abstract}

Keywords PSP plate $\cdot$ Artefacts $\cdot$ Disinfection $\cdot$ Envelope barrier

\section{Introduction}

Unlike conventional disposable film, the digital imaging systems (both charge-coupled device (CCD)/complementary metal-oxide semiconductor (CMOS) sensors and photostimulable phosphor (PSP) plates) that allow exposing multiple patients, raise concerns in terms of infection control [18,21]. PSP plates are used commonly in dental clinics for intraoral imaging because of their flexibility, absence of an electrical cord, wider exposure latitude, and less patient discomfort compared with others [8]. However, these plates cannot be heat sterilized, rubbed with disinfectants, or completely

Umut Pamukcu

dtumutpamukcu@gmail.com

1 Department of Dentomaxillofacial Radiology, Faculty of Dentistry, Gazi University, 2. Sokak No: 4 Emek, Ankara, Turkey

2 Department of Statistics, Faculty of Sciences, Hacettepe University, Ankara, Turkey immersed in a high-level disinfectant $[18,34]$. Therefore, it is important to use a plastic envelope as a barrier to avoid cross-contamination of the PSP plate with the patient's oral fluids, such as saliva and blood or body fluids from handling, and exposure to an unwanted light source [21,26].

At present, the COVID-19 pandemic is the most important health problem effecting the whole world. SARS-CoV 2 causing COVID-19, can persist on inanimate surfaces for 4 $\mathrm{h}$ up to 7 days depending on the temperature, humidity, type of surface, and virus load and has been identified in both blood and saliva [27]. Dental radiology procedures, especially intraoral radiography, can be the source of COVID19 transmission for both staff and patients, due to the fact that infection spreads easily, especially from the oral region by saliva and/or blood [29]. Therefore, current infection control practices should be revised and stricter protocols should be developed for preventing the transmission during the intraoral radiography procedures [20]. Hypochlorite ( $0.5 \%$ for blood and body fluids, $0.1 \%$ for environmental 
disinfection), 70-90\% ethanol and $>0.5 \%$ hydrogen peroxide are recommended disinfectants against COVID-19 [24].

Although envelopes are routinely used in infection control of PSP plates as a barrier, many studies have indicated that using envelopes alone is not sufficient for preventing potential leakage and thus contamination $[11,12,15,16$, $18,21,26]$. Alternately, when the plate is removed from the envelope for scanning there is a contact possibility of the plate with the contaminated envelope and gloves [18]. If the plates are contaminated before the scanning process through the envelopes, it can cause a cross-contamination risk for the other plates, processing equipment, and finally other patients or clinic staff $[11,19]$. Hence, additional methods, as using double barriers and/or disinfecting the barriers before removing the sensors, are recommended for effective infection control, especially during the COVID-19 pandemic, when infection control is even more vital $[5,7$, $11,14,22,32,33]$. Because, intraoral radiographs can trigger the coughing, gagging, retching, or vomiting that produce aerosols that the SARS-CoV 2 can persist in for long periods of time.

Although PSP plates have many advantages, incorrect manipulations and technical errors both in the acquisition and processing of the images may cause distinctive radiographic errors and artefacts [3]. During multiple usages, PSP plates are subjected to excessive mechanical forces, such as excessive bending, positioning device pressure, or bite force, various disinfecting chemicals, such as alcohol, and body fluids such as skin oil, saliva, or blood that can damage their active phosphor photostimulating luminescence layer $[1,3$, $4,17,28,31,34,35]$. This damage causes signal voids that manifests radiologically radiopaque artefacts which results in permanent degradation of all subsequent images recorded with the plate and effects the image quality or complete diagnosis and leads to a remake of the radiograph that is inconsistent with ALADA (as low as diagnostically acceptable) $[1,28,35]$. Artefacts caused by chemical solutions such as disinfections are seen in patch-form at the borders of the images, consistent with peeling [34]. Especially in a study investigating mechanical damage, above a load application of 20 or $50-100 \mathrm{~g}$ according to plate brand caused visible scratches and in an another study the artefacts were observed after a $40 \mathrm{n}$ force loading $[2,6]$. The cumulative damage caused by the continuous use influences their lifespan negatively [3].

To the best of the authors' knowledge, except for the microbiological studies, there is no study that has examined the image artefacts caused by wiping the enveloped PSP plate with disinfection tissue and spraying disinfection solution onto it. In addition, there is no study that has examined the effect of using a single or double envelope on artefact formation, either. The aim of this study was to investigate the damage-related artefacts that two different disinfection methods and two different enveloping methods would cause on PSP plate images.

\section{Materials and methods}

Eight new (unused) VistaScan Imaging Plate PLUS, size 2 (Dürr Dental, Bietigheim-Bissingen, Germany) PSP plates to be used in the study were first cleared of any possible residual background effects by the powerful light source in the scanner. Thus, the plates were restored to their original state, with empty memories. To compare the possible artefacts caused by the disinfection process-related damage, the test images were acquired as a reference. If no artefacts were detected by the three maxillofacial radiologists on the test images, the plates were included in the study. The test images, and the consecutive images after the disinfection process were acquired with an aluminum (Al) step wedge made of $99.5 \%$ pure $\mathrm{Al}$ with nine-step in increments of two millimeters. PSP plates were divided into four groups (A, $\mathrm{B}, \mathrm{C}, \mathrm{D})$, two in each group, according to the two different disinfection and two enveloping methods to be applied. The groups were formed according to two variables: (a) enveloping the plates with single or double envelopes and (b) two different disinfection methods (spraying disinfection solution or wiping with disinfectant tissue) applied onto the enveloped plates. Each plate was used only in its own group during the study and possible artefacts were evaluated based on its test image. The plates were enveloped by Soredex Opti Bags (PaloDex Group Oy, Tuusula, Finland) and sealed according to the manufacturer's instructions. The disinfection process was carried out immediately to the enveloped plates after the X-ray exposures. The four enveloped plates, in groups A and B were wiped with an alcohol containing disinfectant tissue [34], and onto the four in groups $\mathrm{C}$ and $\mathrm{D}$ an alcohol containing disinfectant solution was sprayed [10]. The plates in $\mathrm{A}$ and $\mathrm{C}$ groups were enveloped with single envelope and in $\mathrm{B}$ and $\mathrm{D}$ groups were enveloped with double envelopes. Both disinfectants used in this study contained at least $70 \%$ alcohol, because this level is effective for COVID-19 and other oral pathogens. The disinfectant tissue used was Bioflex Professional (Olce Kozmetik, Istanbul, Turkey) containing 70\% ethyl alcohol, and the disinfectant solution was ANIOSRUB 85NPC (ANIOS, Lille-Hellemmes, France) containing 70\% ethanol. The disinfection process was applied to each enveloped plate in a series, where the number gradually increased in total (cumulatively): 5, 10, 15, 20, 25, 30, 35, 40, 45, 50, 55 and 60 times. In groups A and B four enveloped plates were wiped with gentle finger pressure five times with a disinfectant tissue, each time for $10 \mathrm{~s}$ with 1-min intervals after the exposure, then the plate was removed and scanned immediately and the image was recorded. Thus, a total of 12 
images of each plate were acquired by repeating the same processes for each plate in these groups, in the same way, each time. The same process was repeated for four plates in groups $\mathrm{C}$ and $\mathrm{D}$ by spraying a disinfectant solution onto the enveloped plates five times with 1-min intervals after the exposure, then the plate was removed and scanned immediately and the image was recorded. The disinfection solution was sprayed from a distance of $30 \mathrm{~cm}$ in accordance with the manufacturer's instructions. Thus, in the groups, where the disinfectant solution was used directly, a total of 12 images of each plate were acquired by repeating the same processes for each plate, in the same way, each time.

To achieve standardization in radiographic image acquisition, a plexiglass appliance with dimensions of $6.1 \times 4.8 \times 3.6 \mathrm{~cm}$ was used. This custom-made appliance had a slot in which the enveloped PSP plate could be exactly placed (Fig. 1). The construction of the appliance allowed a fixed distance with a perpendicular alignment repeatable geometry between the X-ray source and the PSP plate. The source-to-plate distance was set at $33.7 \mathrm{~cm}$. The exposured surface of the appliance was prepared with a thickness of $3.2 \mathrm{~cm}$ to imitate the buccal soft tissue [30]. The AI step wedge was fixed on the side of the appliance, where the sensitive surface (exposed surface) of the plate was faced. For stabilization, the position indicating device and the appliance that fixed to it were positioned in the same horizontal position during the study.

For radiographic imaging, a standard X-ray machine (CCX radiography unit, Trophy, Instrumentarium, Tuusula, Finland) with $1.5 \mathrm{~mm} \mathrm{Al}$ equivalent total filtration, operating at $70 \mathrm{kV}, 8 \mathrm{~mA}, 0.3 \mathrm{~s}$ exposure parameters was used. After the X-ray exposure, one of two disinfection procedures was applied onto the enveloped PSP plate, depending on the group in which it belonged. The sealed edge of the envelope(s) was cut with a pair of clean scissors and the PSP plates were removed carefully by holding the edges with minimal contact and carried to a dark room in a paper cup, where they would be scanned. The operator removed the

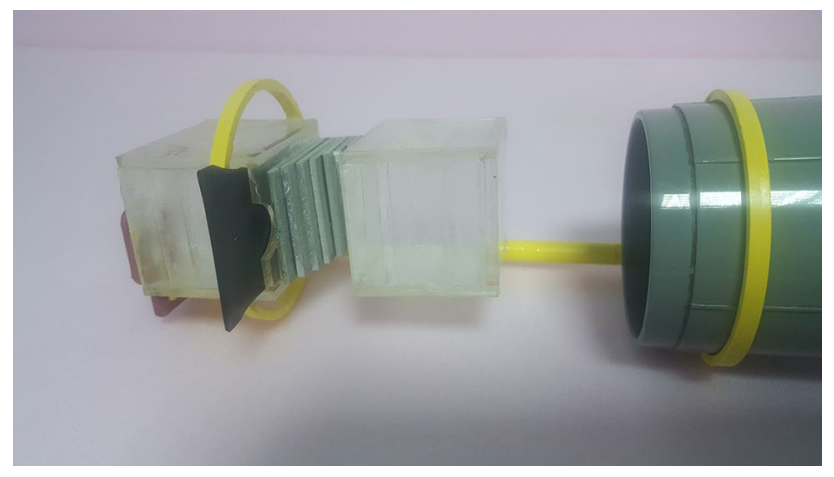

Fig. 1 Photograph of the custom-made plexiglass appliance with a slot and AI step wedge gloves that came into contact with the envelopes during the disinfection process and removed the plates with new gloves, in case they had disinfectant residue on them. All scanning procedures were performed with a VistaScan Combi (Dürr Dental GmbH \& Co. KG, Bietigheim-Bissingen, Germany) scanner using the standard scanning mode allowing a pixel size of $50 \mu \mathrm{m}$ and a theoretical spatial resolution of 10-lp/ $\mathrm{mm}$. These procedures were repeated 12 consecutive times with new envelope(s) and the same PSP plate after each exposure to mimic the clinical conditions [34]. Including the eight test images a total of 104 digital radiographic images were recorded with their own group name that was predetermined (Fig. 2). All radiography exposures, disinfection and scanning procedures were performed by the same researcher.

The 12 images of each plate were evaluated in terms of the presence of artefact based on their own test image by three dentomaxillofacial radiologists (Obs-1, Obs-2, and Obs-3) two with at least 15 years, and one with at least 3 years of experience. Before the study images were evaluated, the observers were asked to evaluate the PSP plate images of the patients previously obtained in the clinic. When encountered with a controversial situation, three observers inspected the image together and came to a consensus on the presence/absence of the artefact. This consensus finding was defined to be the gold standard, and thus the observers were calibrated. The evaluation of the images was done on the same 24-inch medical monitor (Philips, Luchu Hsiang, Taiwan) with an ideal screen display (resolution: $1920 \times 1080$ pixels) provided with an NVIDIA QUADRO FX 380 graphics card in a dimmed and quiet room from a distance of approximately $50 \mathrm{~cm}$. The observers scored the 12 images of each plate independently, in a system, where only the name of the groups was indicated and they were blind to all other variables. The score categories used to evaluate the artefacts of the image were; $1=$ no artefact on the image, $2=$ presence of artefact less than $0.5 \mathrm{~cm}$ wide on the image, and $3=$ presence of artefact larger than $0.5 \mathrm{~cm}$ wide on the image [34]. A second scoring session was held 2 weeks after the first evaluation to measure the observer's repeatability. The obtained data were recorded in a form that was specially prepared for this study.

Ethical approval was not obtained, because this research study did not include human subjects, patient data, and human tissue.

\section{Statistical analysis}

In this study, depending on the distributional violations, nonparametric statistical analysis was used. The comparisons were evaluated using Kruskal-Wallis and post-hoc tests. The reproducibility and repeatability of the measurements were evaluated using the Intraclass Correlation Coefficients 
Eight new PSP plates were distributed to four groups, two in each group. The plates were firstly cleared from any background effect by means of the strong light source built in the scanner. Test images were then acquired to see that there were no artefacts on the plates and as a reference image. According to the group, the plates were enveloped with single or double envelopes, and two different disinfection methods were applied.

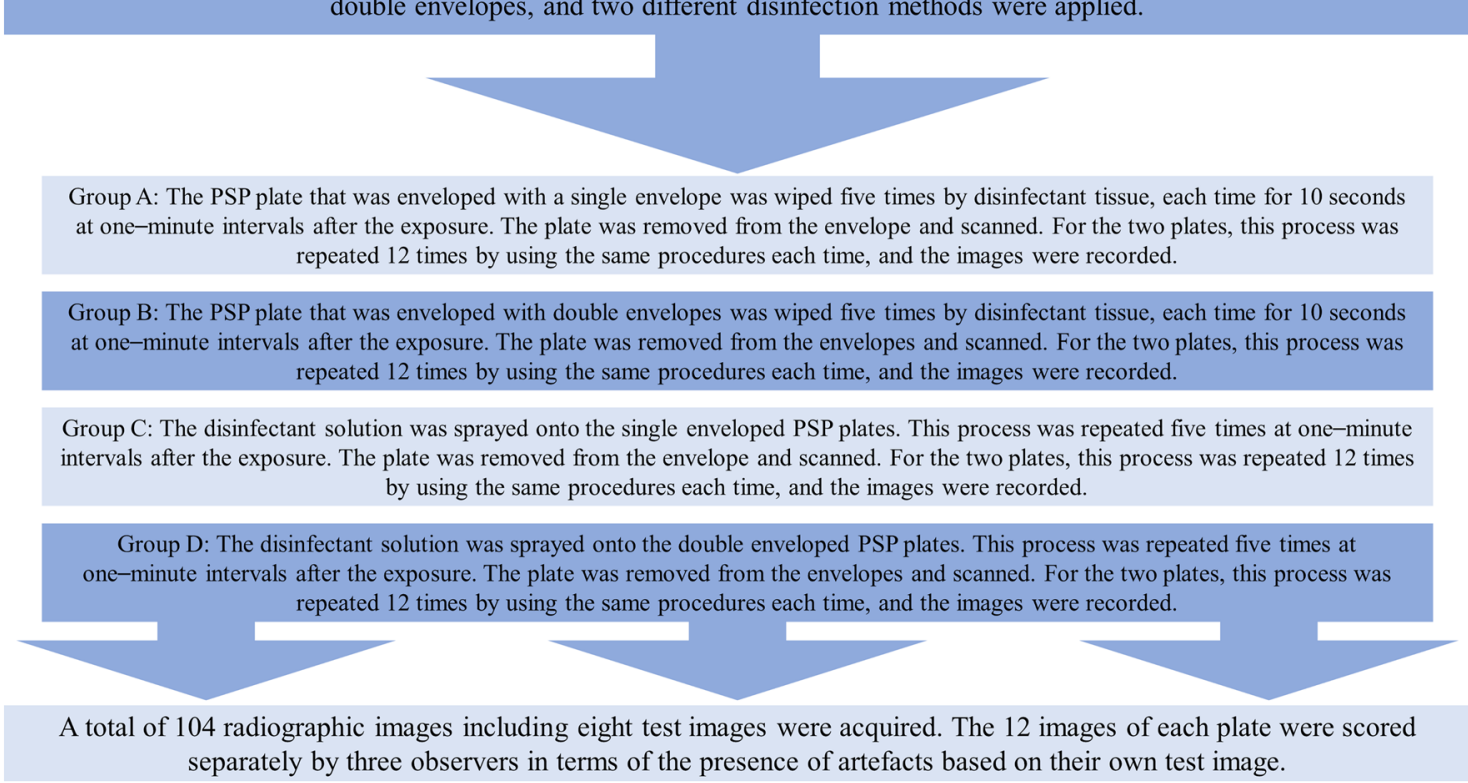

Fig. 2 Flow-process diagram of study method

(ICCs). The data obtained were analyzed using the SPSS version 23.0 (Armonk, New York). Less than $0.05 p$ value was accepted statistically significant.

\section{Results}

As a result of the 1 st and 2 nd evaluations at 2 -week intervals of Obs-1, Obs-2 and Obs-3, the same scores were determined for all images and are given in Table 1. Three observers in their two evaluations determined the same artefacts scores on the same images after the 3 rd exposure in Group C-2 (score-3 artefact) (Fig. 3). Artefacts were in patch-form at the borders of the images as shown by the arrows in Fig. 3. As aforementioned, Group C-2 represented the plate that was enveloped with a single envelope and sprayed with alcohol-containing solution.

The ICC value was very high and considered as perfect correlation for intra-observer reliability $(\mathrm{ICC}=1.00$,
Table 1 Scores of 1 st and 2nd artefact evaluations at 2-week intervals of Obs- 1 , Obs-2, and Obs-3 on the consecutive images of PSP plates following the disinfection procedure in four groups

\begin{tabular}{|c|c|c|c|c|c|c|c|c|}
\hline \multirow[t]{2}{*}{ Images } & \multicolumn{2}{|c|}{ Group A } & \multicolumn{2}{|c|}{ Group B } & \multicolumn{2}{|c|}{ Group C } & \multicolumn{2}{|c|}{ Group D } \\
\hline & A-1 & A-2 & B-1 & B-2 & $\mathrm{C}-1$ & $\mathrm{C}-2$ & D-1 & D-2 \\
\hline Test image & 1 & 1 & 1 & 1 & 1 & 1 & 1 & 1 \\
\hline 1st image & 1 & 1 & 1 & 1 & 1 & 1 & 1 & 1 \\
\hline 2nd image & 1 & 1 & 1 & 1 & 1 & 1 & 1 & 1 \\
\hline 3rd image & 1 & 1 & 1 & 1 & 1 & 3 & 1 & 1 \\
\hline 4th image & 1 & 1 & 1 & 1 & 1 & 3 & 1 & 1 \\
\hline 5th image & 1 & 1 & 1 & 1 & 1 & 3 & 1 & 1 \\
\hline 6th image & 1 & 1 & 1 & 1 & 1 & 3 & 1 & 1 \\
\hline 7th image & 1 & 1 & 1 & 1 & 1 & 3 & 1 & 1 \\
\hline 8th image & 1 & 1 & 1 & 1 & 1 & 3 & 1 & 1 \\
\hline 9th image & 1 & 1 & 1 & 1 & 1 & 3 & 1 & 1 \\
\hline 10th image & 1 & 1 & 1 & 1 & 1 & 3 & 1 & 1 \\
\hline 11th image & 1 & 1 & 1 & 1 & 1 & 3 & 1 & 1 \\
\hline 12th image & 1 & 1 & 1 & 1 & 1 & 3 & 1 & 1 \\
\hline
\end{tabular}




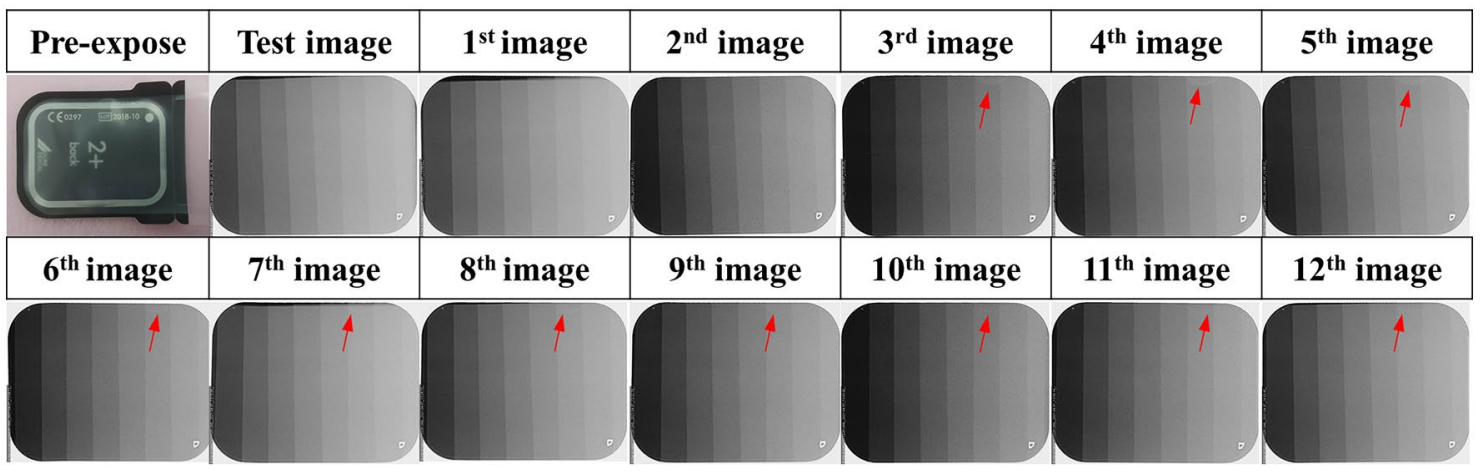

Fig. 3 Consecutive 12 images after the exposures and disinfection processes, test image, and pre-exposure photograph of the Group C-2 PSP plate enveloped with a single envelope and sprayed with alcohol-containing solution

$p=0.000)$. The inter-observer reliability was also considered perfectly correlated (ICC $=1.00, p=0.000$ ).

For comparing methods, the Kruskal-Wallis test was used. According to the test result, in terms of artefact score, the difference between the four methods was found statistically significant $(p=0.000<0.05)$. Post-hoc comparisons showed that the difference between the artefact scores of Group A (single envelope, wiped with disinfectant tissue), Group B (double envelopes, wiped with disinfectant tissue) and Group D (disinfectant sprayed onto double envelopes) was not statistically significant, and Group C (disinfectant sprayed onto single envelope) artefact scores was higher than the other three, and the difference was statistically significant $(p=0.000<0.05)$.

Before starting the study, the total time of enveloping and disinfection process in each group was measured. The results were $6.30 \mathrm{~min}$ for Group A, $7.58 \mathrm{~min}$ for Group B, $5.48 \mathrm{~min}$ for Group C, and 7.14 min for Group D.

\section{Discussion}

The results may indicate that any disinfection method applied onto the enveloped plate does not cause artefacts on images if the PSP plate is enveloped with a sufficient barrier, such as double envelopes. In another aspect, it could be claimed that spraying an alcohol containing disinfection solution directly onto the plate with single envelope also increases the likelihood of an artefact rather than wiping with alcohol-containing disinfection tissue.

There is no agreed protocol or standard procedure for effective infection control of PSP plates, which has increased in importance especially during the COVID-19 pandemic. Especially against COVID-19, a minimum of 1-min contact time with the disinfectant solution is advised [14]. Intermediate level disinfectants (70\% ethyl alcohol, 70\% isopropyl alcohol) can be used for disinfection of radiography items on a daily basis or when contaminated $[14,19,25]$. Recommendations that emerged as results of studies on infection control of PSP plates were as follows; checking the integrity of the barrier visually or by a leakage test, making the patient gargle with chlorhexidine, disinfecting the plate before placement into the envelope and after removing, using an additional barrier in high-risk situations, disinfecting the enveloped plate $[7,10,13,18,35]$. All the processes must be under aseptic conditions and with minimal handling [10]. Methods of disinfecting the enveloped plate or directly the plate were wiping with alcohol-containing or alcohol-impregnated tissue, the UV-light built into the scanner and the ethylene oxide gas sterilization [15, 26, 33, 34]. Manufacturers have proposed different solutions for hygiene problems that may arise during the use of PSP plate systems. A manufacturer (Brighouse, UK; DB dental equipment) has proposed the use of 2-propanol for cleaning the PSP plates [34]. The manufacturer of the Digora ${ }^{\circledR}$ Optime UV unit (Soredex, Orion Corporation, Helsinki, Finland) declared the product has internal UV-disinfection features in scanning procedure that minimize cross-contamination risk [34]. However, this type of UV-disinfection system is not available on all PSP plate scanners and subsequent installation in the system can create a high cost [26]. In this study, disinfection tissue and spray solution containing $70 \%$ alcohol which is effective against COVID-19 and the other oral pathogens were used.

Studies determined and classified the image errors and artefacts specific to PSP technology [4, 9, 23, 31]. Artefacts on PSP plate images basically have two main causative factors as damage and dirt on the photo-stimulating luminescence phosphor surface, especially due to multiple and repetitive uses $[1,3,4,17]$. The damage occurs because of physical (mechanical) or chemical factors that the plate is subjected to. It was reported, when a force greater than $40 \mathrm{n}$ was applied to the enveloped plate the artefacts were observed on the images [6]. In another study, it was found 
that loading of $20 \mathrm{~g}$ or $50-100 \mathrm{~g}$ directly on the plate, depending on the plate brand, caused scratches on the sensitive surface of the plate [2]. Wenzel et al. [34] tested the formation of possible image artefacts by wiping the plates directly with two different alcohol containing disinfection tissues. For eliminating the effect of mechanical effect of wiping, they wiped the PSP plates with a gentle pressure, and reported that ethanol caused more severe artefacts compared to 2-propanol [34]. Since ethanol has been reported to cause more serious artefacts than 2-propanol, it can be concluded that the damage is caused by the chemical structure of the disinfectant used [34]. Therefore, in this study, light finger pressure was used to wipe the enveloped plates with alcohol-impregnated tissues. Thus, it was aimed only to investigate the artefacts that would occur due to chemical damage when the disinfectant reaches the sensitive surface of the plate. Removing the PSP plate from the envelope that was contaminated with oral fluids may cause a major problem for cross-contamination. The recommended methods of the disinfection of PSP plates are using double envelopes and spraying disinfectant on the enveloped plate or directly on the PSP plate (usually containing alcohol) or wiping with disinfectant impregnated tissue. There were microbiological studies that measure the effectiveness of the disinfection of the "enveloped" plate with alcohol before removing the plate [21, 26, 33]. In this study, instead of applying the disinfectant directly to the plate, the enveloped plate disinfection method was also chosen. According to the results of this study, it can be said that these methods did not cause too much damage to the PSP plates and consequently image artefacts. In Group C, where an artefact was observed on only one of two plates images, the plate was enveloped with a single envelope and disinfected with spraying solution. The damage-related artefact formation can be the result of enveloping the plate with a single envelope rather than double envelopes in one respect. In another aspect, it can also be interpreted as spraying the alcohol-containing disinfection directly rather than wiping. Therefore, it can be claimed spraying disinfection directly onto the enveloped plate with a single envelope increases the risk of artefact formation in routine clinical practice.

Hokett et al. [11] reported a perforation rate of $44-51 \%$ when using a single plastic barrier for direct digital sensors under clinical conditions and recommended the use of a latex finger cot to significantly reduce the perforation rate. Choi et al. [5] found this rate between 22 and 58\%, and the perforation occurred less in the thick material group and more in the thin group. This high perforation rate of the plastic barrier in direct digital sensors system brings the safety of the single-barrier technique into question for all intraoral digital receptors including PSP plates. Furthermore, the perforation rate may vary by material type or barrier thickness. Although the present study was planned as an in vitro study, the main aim was imitating as much as the possible routine clinical conditions in which patients were being imaged with intraoral digital PSP plates. Therefore, the envelopes were used as they were taken out of their boxes, which the manufacturer checked and packed, and so no leakage test was applied. The leakageinduced artefact that may occur because of using the envelopes without testing just like they are used in routine clinical conditions was also one of the factors that was investigated in this study. This is in line with the authors' findings that a damagerelated artefact is an increased possibility due to reduced protection when a single envelope is used and the disinfection is sprayed directly as solution.

A limitation of this study is that different brands of envelopes and different disinfectants have not been tested. These variable conditions can be investigated in further studies. Another limitation is while we evaluated the effect of the disinfectant method on artefact formation, but not on image quality. This case also may be the subject of future studies, too.

\section{Conclusion}

When the total times of the enveloping and disinfection process for each group separately were compared, it was observed enveloping with double envelopes took notably more time than one envelope and wiping with tissue took slightly longer than spraying. Although the other results showed artefacts were never observed when double envelopes and wiping with tissue were used and these methods were superior in terms of disinfection-artefact formation, it can be said these will cause a significant loss of time in routine clinical practice. In addition, the researcher who performed the procedures emphasized that enveloping with double envelopes was very difficult in terms of manipulation. In addition, wiping with a tissue and enveloping with double envelopes have higher costs and cause environmental pollution because of using more consumables.

Funding No funding was received for this study.

\section{Declarations}

Conflict of interest The authors declare no conflict of interest.

Ethics approval This article does not contain any studies with human or animal subjects performed by the any of the authors.

\section{References}

1. Bedard A, Davis T, Angelopoulos C. Storage phosphor plates: how durable are they as a digital dental radiographic system? J Contemp Dent Pract. 2004;5:57-69.

2. Borch V, Østergaard M, Gotfredsen E, Wenzel A. Identification of errors particular for intraoral radiographs captured with 
digital receptors (with an English summary). Danish Dent J. 2008;112:720-31.

3. Caliskan A, Sumer AP. Definition, classification and retrospective analysis of photostimulable phosphor image artefacts and errors in intraoral dental radiography. Dentomaxillofac Radiol. 2017;46:20160188. https://doi.org/10.1259/dmfr.20160188.

4. Chiu HL, Lin SH, Chen CH, Wang WC, Chen JY, Chen YK, et al. Analysis of photostimulable phosphor plate image artifacts in an oral and maxillofacial radiology department. Oral Surg Oral Med Oral Pathol Oral Radiol Endod. 2008;106:749-56. https://doi.org/ 10.1016/j.tripleo.2008.01.003.

5. Choi JW. Perforation rate of intraoral barriers for direct digital radiography. Dentomaxillofac Radiol. 2015;44:20140245. https://doi. org/10.1259/dmfr.20140245.

6. de Moura G, Vizzotto MB, Tiecher P, Arus NA, Silveira H. Benefits of using a photostimulable phosphor plate protective device. Dentomaxillofac Radiol. 2021;50:20200339. https://doi.org/10.1259/ dmfr.20200339.

7. de Souza TM, de Castro RD, de Vasconcelos LC, Pontual AD, de Moraes Ramos Perez FM, Pontual ML. Microbial contamination in intraoral phosphor storage plates: the dilemma. Clin Oral Investig. 2017;21:301-7. https://doi.org/10.1007/s00784-016-1790-7.

8. Farman AG, Farman TT. A comparison of 18 different X-ray detectors currently used in dentistry. Oral Surg Oral Med Oral Pathol Oral Radiol Endod. 2005;99:485-9. https://doi.org/10.1016/j.tripl eo.2004.04.002.

9. Gulsahi A, Secgin CK. Assessment of intraoral image artifacts related to photostimulable phosphor plates in a dentomaxillofacial radiology department. Niger J Clin Pract. 2016;19:248-53. https:// doi.org/10.4103/1119-3077.164338.

10. Gumru B, Tarcin B, Idman E. Cross-contamination and infection control in intraoral digital imaging: a comprehensive review. Oral Radiol. 2021;37:180-8. https://doi.org/10.1007/ s11282-020-00452-z.

11. Hokett SD, Honey JR, Ruiz F, Baisden MK, Hoen MM. Assessing the effectiveness of direct digital radiography barrier sheaths and finger cots. J Am Dent Assoc. 2000;131:463-7. https://doi.org/10. 14219/jada.archive.2000.0202.

12. Hubar J, Gardiner D. Infection control procedures used in conjunction with computed dental radiography. Int J Comput Dent. 2000;3:259.

13. Hunter A, Kalathingal S, Shrout M, Plummer K, Looney S. The effectiveness of a pre-procedural mouthrinse in reducing bacteria on radiographic phosphor plates. Imaging Sci Dent. 2014;44:149-54. https://doi.org/10.5624/isd.2014.44.2.149.

14. Ilhan B, Bayrakdar IS, Orhan K. Dental radiographic procedures during COVID-19 outbreak and normalization period: recommendations on infection control. Oral Radiol. 2020;36:395-9. https://doi. org/10.1007/s11282-020-00460-z.

15. Kalathingal S, Youngpeter A, Minton J, Shrout M, Dickinson D, Plummer K, et al. An evaluation of microbiologic contamination on a phosphor plate system: is weekly gas sterilization enough? Oral Surg Oral Med Oral Pathol Oral Radiol Endod. 2010;109:457-62. https://doi.org/10.1016/j.tripleo.2009.09.035.

16. Kalathingal SM, Moore S, Kwon S, Schuster GS, Shrout MK, Plummer K. An evaluation of microbiologic contamination on phosphor plates in a dental school. Oral Surg Oral Med Oral Pathol Oral Radiol Endod. 2009;107:279-82. https://doi.org/10.1016/j.tripleo. 2008.05.025

17. Kalathingal SM, Shrout MK, Comer C, Brady C. Rating the extent of surface scratches on photostimulable storage phosphor plates in a dental school environment. Dentomaxillofac Radiol. 2010;39:179_ 83. https://doi.org/10.1259/dmfr/28972644.

18. MacDonald DS, Waterfield JD. Infection control in digital intraoral radiography: evaluation of microbiological contamination of photostimulable phosphor plates in barrier envelopes. J Can Dent Assoc. 2011;77:93.
19. Mallya S, Lam E. White and pharoah's oral radiology e-book: principles and interpretation: Second South Asia Edition E-Book: Elsevier India; 2019.

20. Meng L, Hua F, Bian Z. Coronavirus disease 2019 (COVID-19): emerging and future challenges for dental and oral medicine. J Dent Res. 2020;99:481-7. https://doi.org/10.1177/0022034520914246.

21. Negron W, Mauriello SM, Peterson CA, Arnold R. Cross-contamination of the PSP sensor in a preclinical setting. J Dent Hyg. 2005;79:8.

22. Nikkerdar N, Akya A, Khavid A, Karimi A, Emadi S. Effectiveness of two types of photostimulable phosphor plate plastic barrier envelopes for prevention of microbiological contamination. Pesqui Bras Odontopediatria Clin Integr. 2020. https://doi.org/10.1590/pboci. 2020.047.

23. Oestmann JW, Prokop M, Schaefer CM, Galanski M. Hardware and software artifacts in storage phosphor radiography. Radiographics. 1991;11:795-805. https://doi.org/10.1148/radiographics.11.5.19473 16.

24. Organization WH. Cleaning and disinfection of environmental surfaces in the context of COVID-19: interim guidance, 15 May 2020. World Health Organization, 2020.

25. Palenik CJ. Infection control practices for dental radiography. Dent Today. 2004;23:52-5.

26. Peker I, Peker E, Basman A, Akca G, Odabas M, Haciosmanoglu N, et al. A pilot study of the effects of a vacuum sealing barrier method for photostimulable phosphor plates regarding plate damage and prevention of microbiologic cross-contamination. Oral Surg Oral Med Oral Pathol Oral Radiol. 2018;126:283-90. https://doi.org/10. 1016/j.oooo.2018.05.015.

27. Revel MP, Parkar AP, Prosch H, Silva M, Sverzellati N, Gleeson F, et al. COVID-19 patients and the radiology department—advice from the European Society of Radiology (ESR) and the European Society of Thoracic Imaging (ESTI). Eur Radiol. 2020;30:4903-9. https://doi.org/10.1007/s00330-020-06865-y.

28. Roberts MW, Mol A. Clinical techniques to reduce sensor plate damage in PSP digital radiography. J Dent Child (Chic). 2004;71:169-70.

29. Saki M, Haseli S, Iranpour P. Oral radiology center as a potential source of COVID-19 transmission. Points to consider. Acad Radiol. 2020;27:1047-8. https://doi.org/10.1016/j.acra.2020.04.040.

30. Schropp L, Alyass NS, Wenzel A, Stavropoulos A. Validity of wax and acrylic as soft-tissue simulation materials used in in vitro radiographic studies. Dentomaxillofac Radiol. 2012;41:686-90. https:// doi.org/10.1259/dmfr/33467269.

31. Shetty CM, Barthur A, Kambadakone A, Narayanan N, Kv R. Computed radiography image artifacts revisited. AJR Am J Roentgenol. 2011;196:W37-47. https://doi.org/10.2214/AJR.10.5563.

32. Thomas LP, Abramovitch K. Infection control for dental radiographic procedures. Tex Dent J. 2005;122:184-8.

33. Wenzel A, Frandsen E, Hintze H. Patient discomfort and crossinfection control in bitewing examination with a storage phosphor plate and a CCD-based sensor. J Dent. 1999;27:243-6. https://doi. org/10.1016/s0300-5712(98)00063-3.

34. Wenzel A, Kornum F, Knudsen M, Lau EF. Antimicrobial efficiency of ethanol and 2-propanol alcohols used on contaminated storage phosphor plates and impact on durability of the plate. Dentomaxillofac Radiol. 2013;42:20120353. https://doi.org/10.1259/dmfr.20120 353.

35. Wenzel A, Moystad A. Work flow with digital intraoral radiography: a systematic review. Acta Odontol Scand. 2010;68:106-14. https:// doi.org/10.3109/00016350903514426.

Publisher's Note Springer Nature remains neutral with regard to jurisdictional claims in published maps and institutional affiliations. 